THE FETISH REVISITED 
This page intentionally left blank 
J. LORAND MATORY

\section{THE FETISH \\ REVISITED}

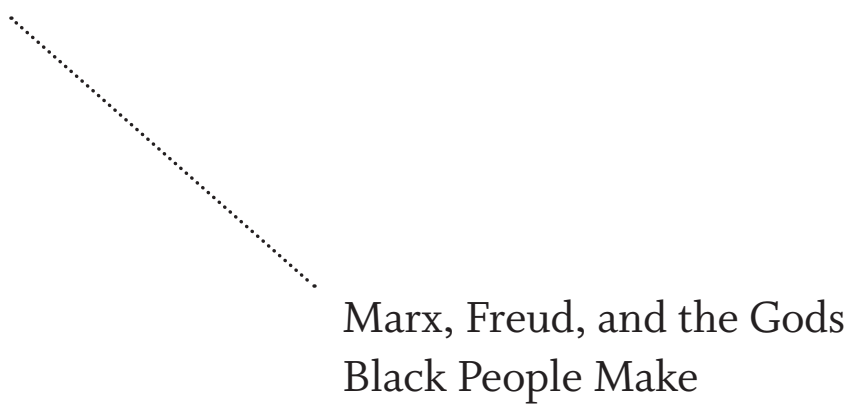


(C) 2018 Duke University Press

All rights reserved

Printed in the United States of America

on acid-free paper $\infty$

Designed by Julienne Alexander

Typeset in Whitman by Westchester Publishing Services

Library of Congress Cataloging-in-Publication Data

Names: Matory, James Lorand, author.

Title: The fetish revisited : Marx, Freud, and the gods Black

people make / J. Lorand Matory.

Description: Durham : Duke University Press, 2018. |

Includes bibliographical references and index.

Identifiers: LCCN 2018010546 (print)

LCCN 2018017703 (ebook)

ISBN 9781478002437 (ebook)

ISBN 9781478000754 (hardcover : alk. paper)

ISBN 9781478001058 (pbk. : alk. paper)

Subjects: LCSH: Fetishism. | Africa-Religion. |

Marx, Karl, 1818-1883. | Freud, Sigmund, 1856-1939.

Classification: LCC GN472 (ebook) | LCC GN472 .M38 2018 (print)|

DDC 306.77/7-dc23

LC record available at https://lccn.loc.gov/2018010546

Cover art: Kota reliquary statue (SABA Collection EO12).

More information on this image and others from the Sacred

Arts of the Black Atlantic Collection at Duke University is available at https://sacredart.caaar.duke.edu/. 
DEDICATED TO

OLUBUNMI FATOYE-MATORY

ọmọ ọṣun

ỌMỌ ALÁYÒ

ỌMọ ALÁÙRÍN

AÙRIN ÀYÀN ELÙ

AÙRIN ÀYÁNKÓRO

MÀMÁ AYỌ

ÌYÁ ADÚMÁRADỌN

OLÓLÙFÉ MI

ÒDÒDÓ MI

IYÙN MI 